\title{
Immune Response in a Pediatric Cancer Patient after a One-Week Skiing Intervention
}

\author{
Nicolas Kurpiers ${ }^{1}$, Nico de Lazzari ${ }^{1}$, Nils von Neuhoff ${ }^{2}$ and Stefan Flohr ${ }^{1}$ \\ ${ }^{1}$ Department of Sports Science, University of Hildesheim, Germany \\ ${ }^{2} A M L$ Diagnostic and Research Laboratory, Clinic of Pediatrics, University Hospital Essen, Germany

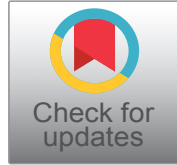

*Corresponding author: Nicolas Kurpiers, PhD, Department of Sports Science, University of Hildesheim, Universitatsplatz 1, 31141 Hildesheim, Germany, Tel: +49-5121-883-11918

\begin{abstract}
Moderate physical activity possesses positive effects on the immune system function. Numerous studies investigated such effects also in cancer patients. As most studies were conducted on adults, much less is known in children and adolescents. Moreover, most studies were conducted under laboratory conditions in order to control the duration and intensity of the activity. However, daily life also includes outdoor activities.

The aim of the present study was to investigate immunological parameters in a pediatric cancer survivor (8 years) suffering Acute Myeloid Leukemia (AML) who underwent bone marrow transplantation. The values were compared to those of a healthy control group (CG; $N=10$ ). Blood samples were taken at the first (pre-test) and at the last day (post-test) of a winter sports camp by using a portable flow cytometry BD Accuri C6 device.

No significant changes were observed between the preand post-test in the CG. The patient showed an increase in the total lymphocyte population, and in the CD3+ and CD4+ cells, all of them being within the range of variation of the CG. NK-cells increased slightly in the patient, however, both values were below the range of variation of the CG. $B$-Lymphocytes decreased from a value above the range of variation of the CG to a level close to their median value. Although the intensity of the skiing activities was difficult to assess, the patient showed changes in immunological parameters which might be interpreted as an improvement of the immune system in the course of a one-week skiing intervention.
\end{abstract}

\section{Keywords}

Acute myeloid leukemia, Immune system, Rehabilitation, Sports therapy, Winter sports

\section{Introduction}

Numerous studies from the last decades demonstrated the influence of physical activity on the immune system [1-3]. From an epidemiological perspective, the risk of upper respiratory tract infection after physical activity - most intensely investigated in long distance runners - increases after highly intense activities whereas low to moderate intensities were found to decrease the risk [1]. This observation led to the "inverted J hypothesis" which describes the correlation between the intensity of an activity and the immune system response, represented by the risk of infection [4]. As the risk of upper respiratory tract infection might also be related to temporary changes on the mucosa (e.g. drying, cooling, and increased contact to pathogens due to more frequent and deeper breath) during running, investigations of cellular and humoral response to physical activity are a more direct approach to evaluate the effects of sports on immune system function. The respective results are largely in accordance with the epidemiologically obtained results and also suggest an intensity and duration dependent immune reaction with an immunosuppression after highly intense activities [5] but with immunological advantages after moderate activities [6].

The positive effects of moderate physical activity in comparison to a sedentary lifestyle on immune parameters have also been studied in the context of cancer diseases. The research questions concern for instance the aspects prevention [7], rehabilitation [8], and cancer recurrence [9]. The results so far are promising and

Citation: Kurpiers N, de Lazzari N, von Neuhoff N, Flohr S (2019) Immune Response in a Pediatric Cancer Patient after a One-Week Skiing Intervention. Int J Sports Exerc Med 5:134. doi.org/10.23937/24695718/1510134

Accepted: July 03, 2019; Published: July 05, 2019

Copyright: (c) 2019 Kurpiers N, et al. This is an open-access article distributed under the terms of the Creative Commons Attribution License, which permits unrestricted use, distribution, and reproduction in any medium, provided the original author and source are credited. 
based on the seminal works by Schüle [10], physical activity in cancer rehabilitation has largely replaced the former advice of resting and the avoidance of physical "stress" as the most constructive behavior [11].

Most studies on physical activity and cancer were conducted on adults. Only little is known about the effects in pediatric cancer patients. Findings obtained on adults should not be transferred automatically to children and adolescents as it is known that the immune response in (healthy) children partially differs from that of adults [12], caused for instances by changes in the thymus gland in the aging process [13]. Moreover, the variable "physical activity" is difficult to control in children as they show rather often spontaneous physical activities.

Studies on the immunological effects of physical activity on cancer are usually conducted under laboratory environments. This approach is mandatory from a methodological perspective as different variables can be determined, controlled, and isolated accurately such as duration and intensity of activities and other external factors. However, aside the need for such fundamental research conditions, the daily life of cancer patients and cancer survivors does not take place in research laboratories and numerous other factors can affect the immune system function. The aim of the present study was to document changes in immune system parameters in a pediatric cancer survivor in a non-laboratory environment in comparison to corresponding values obtained from a healthy control group. The study was conducted as a pilot-study and a test of feasibility. The study was embedded in a larger, ongoing project in which pediatric cancer patients participate in a one-week winter sport camp together with their families.

\section{Methods}

The study was performed in 2015 on participants of a one-week winter sport camp in Hemsedal (Norway) in an altitude of between $600 \mathrm{~m}$ and $1400 \mathrm{~m}$. The camp was conducted annually from 2012 to 2018 as a larger joining rehabilitation project in cooperation of the University of Hildesheim and the University Hospital of Hannover (both Germany). The aim of the camp as an ongoing project is to remove pediatric cancer survivors together with their families from the exhausting clinical routine and environment in order to support the rehabilitation process. The patients and their families were skiing twice a day under the guidance of experienced instructors for about one and a half to two hours respectively [14]. The children were guided in groups of up to five members. As the instructors were familiar with the individual disease histories of their participants and guided them for the whole week, the instructors were able and free to adopt spontaneously the difficulties and intensities of the exercises and activities in their respective group. The activities comprised skiing-specific technical exercises including exercises of the "One-Ski-
Method" [15] and downhill runs.

\section{The pediatric cancer survivor}

The male patient was diagnosed at an age of five years with acute myeloid leukemia (AML-M5) in May 2012. The treatment of the disease after stratification was performed according to the protocol AML-BFM 2004 [16]. After recurrence of AML in February 2013, the patient was stratified into high risk and underwent a bone marrow transplantation in May 2013. In the course of the allogenic transplantation, the patient's blood type changed from A+ to B-. Thereafter, the boy was treated with immunosuppressant for 1.5 years. He participated at the study at the age of eight years and was out of therapy for 18 months at this time. The patient suffered from severe side effects of the therapy, including impairments of the sense of vision, loss of hearing, enormous increase of body weight (BMI 21.2 with 14-18.9 as normal reference values for his age) and numerous infects. Prior to the winter camp, he was mostly sedentary and due to his generally limited physical condition he arrived at the camp in a wheel chair. The physical condition of the boy improved remarkably and after one week of winter sport activity he was able to ski down about $1000 \mathrm{~m}$ altitude without any assistance.

\section{The control group}

The Control Group (CG) consisted of ten healthy members ( 4 males, 6 females; average age $10.3 \pm 2.0$ years) of the winter camp, most of them being siblings of the patients. They participated at the same activity program as the patients, also grouped according to their skiing abilities and physical condition.

\section{Investigation}

Blood samples were taken from the $V$. brachialis and analyzed at the first (pre-test) and after the sixth and last day (post-test) of the intervention in a field laboratory. The blood was taken in the afternoon between three and four hours after the last skiing session. Criterion for exclusion from the study was an infection at the time of the measurement (retrieved by questionnaire). The measurement device was a portable flow cytometry BD Accuri $\mathrm{C} 6$ which allows for determination of the immune status by measuring the relative concentration of lymphocyte subpopulations. This device has been evaluated as very accurate [10]. For the present study, the total amount of lymphocytes, T-cells (CD3+, $\mathrm{CD} 3+\mathrm{CD} 4+, \mathrm{CD} 3+\mathrm{CD} 8+)$, B-cells (CD19+) and NK-cells (CD16+/CD56+) were determined (BD, Heidelberg, Multitest IMK Kit 50 Tests with BD Trucount Tubes Catalog No. 340504). All data were anonymized after processing. The participants and their parents were informed about the aims of the study and were free to quit their participation at any time without justification. The ethics committee of the Hannover Medical School gave approval. The parents of the participants signed informed 
Table 1: The results of the measurements show the mean values and the standard deviation (SD), the 95\% confidential interval $(\mathrm{Cl})$ of the control group (CG), and the individual values of the patient. $P$-values were obtained from paired $T$-test. Values of the patient which fall outside the $95 \% \mathrm{Cl}$ of the $\mathrm{CG}$ are marked with an asterisk $\left(^{*}\right)$. Values of the patient falling out of the entire range of variation of the CG in pre- and post-test are marked with a double-dagger $\left({ }^{\ddagger}\right)$. For the CG, N = 10, except for CD4+ and CD8+ in the pre-test with $\mathrm{N}=8$ each. The reference values for the shown CDs are $55-83 \%$ (CD 3), 28-57\% (CD 4), 10-39\% (CD 8), $7-31 \%(C D$ 16/56).

\begin{tabular}{|c|c|c|c|c|c|c|c|c|c|}
\hline & \multicolumn{3}{|c|}{ Lymphocytes } & \multicolumn{3}{|l|}{ CD3+ } & \multicolumn{3}{|l|}{ CD4+ } \\
\hline & pre & post & $p$-value & pre & post & $p$-value & pre & post & $p$-value \\
\hline Mean $\pm \mathrm{SD}_{\mathrm{CG}}$ & $30.8 \pm 9.1$ & $29.7 \pm 6.5$ & 0.73 & $68.0 \pm 14.9$ & $73.4 \pm 6.1$ & 0.32 & $44.6 \pm 10.7$ & $47.5 \pm 6.3$ & 0.15 \\
\hline $95 \% \mathrm{Cl}_{\mathrm{CG}}$ & 24.3-37.3 & $25.0-34.4$ & & $57.3-78.7$ & 69.1-77.7 & & $35.7-53.5$ & $43.0-52.0$ & \\
\hline Total range $_{\mathrm{CG}}$ & $20.1-52.3$ & $17.1-40.1$ & & 29.3-81.3 & $60.8-80.6$ & & $31.5-62.5$ & $36.4-59.9$ & \\
\hline \multirow[t]{3}{*}{ Patient } & $18.8^{*}$ & 27.2 & & 62.4 & $79.0^{*}$ & & 37.9 & $53.4^{*}$ & \\
\hline & \multicolumn{3}{|l|}{ CD8+ } & \multicolumn{3}{|c|}{ CD16+/CD56+ } & \multicolumn{3}{|l|}{ CD19+ } \\
\hline & pre & post & $p$-value & pre & post & $p$-value & pre & post & $p$-value \\
\hline Mean $\pm S D_{C G}$ & $25.9 \pm 6.4$ & $23.9 \pm 4.1$ & 0.23 & $11.1 \pm 6.1$ & $7.4 \pm 2.0$ & 0.10 & $11.7 \pm 6.2$ & $12.7 \pm 3.7$ & 0.64 \\
\hline $95 \% \mathrm{Cl}_{\mathrm{CG}}$ & 20.6-31.2 & $21.0-26.9$ & & $6.8-15.4$ & $6.0-8.9$ & & 7.3-16.1 & $10.0-15.3$ & \\
\hline Total range $_{\mathrm{CG}}$ & $18.1-35.3$ & $19.6-30.1$ & & 4.3-19.9 & 4.4-11.6 & & $1.2-20.5$ & 7.6-19.5 & \\
\hline Patient & 22.4 & 23.8 & & $2.9^{* \neq}$ & $3.9^{* \pm}$ & & $23.7^{* \neq}$ & 12.9 & \\
\hline
\end{tabular}
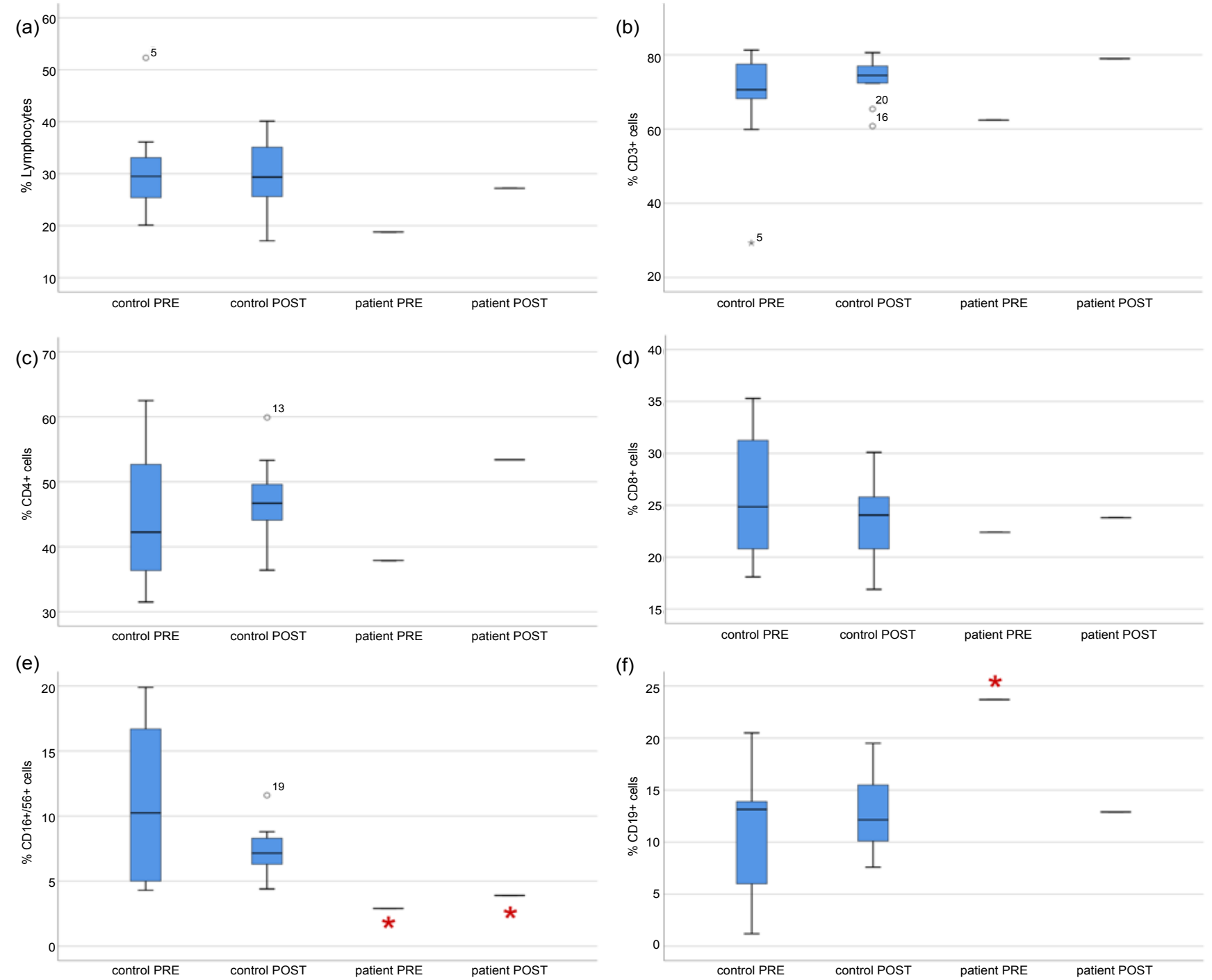

Figure 1: Immune cell response of the patient in comparison to the control group before (PRE) and after (POST) the intervention. 
consent prior to the first test.

The results of the pre-test and the post-test of the CG were analyzed by paired $T$-tests. $P$-values less 0.05 were considered significant. As the statistical analysis of a single value is problematic, the patient's values were compared to the range of variation (total range of variation and $95 \%$ confidential interval) of the CG. The analyses were conducted using the software package IBM SPSS Statistics v23.

\section{Results}

In all six parameters, no significant differences were observed between the pre-test and the post-test in the CG (Table 1).

For the total lymphocyte population, the patient showed a value below the range of variation of the CG in the respective pre-test (Figure 1a). However, the range of variation of the CG was slightly larger in the post-test, i.e. the total range of variation (in pre- and post-test together) of the CP covered the low pre-test value of the patient. In the post-test, the value of the patient was markedly higher compared to the pre-test and close to the median value of the CG. For the CD3+ and CD4+ cells, the values of the patient were markedly higher in the post-test than in the pre-test (Figure $1 \mathrm{~b}$ and Figure $1 c)$, in the post-test even higher than the $95 \%$ confidential interval $(\mathrm{Cl})$ of the $\mathrm{CG}$, but still in the total range of variation. For the CD8+ cells, the values of the patient did not differ markedly between the two measurements and the values were close to the median value of the CG (Figure 1d). The most pronounced differences were measured for the NK-cells (CD16+/CD56+ cells). Here, although the values were slightly higher in the post-test than in the pre-test in the patient, both values were below the range of variation of the CG (Figure 1e). A value markedly higher than the range of variation in the CG was found in the pre-test of the patient for the B-cells (CD19+ cells). In the post-test, however, its value was much lower than in the pre-test and close to the median value of the CG (Figure 1f).

\section{Discussion}

According to the "inverted J hypothesis" and in accordance with numerous epidemiological studies, sport can affect the immune system function in both ways, negative and positive [17-20]. There is considerable agreement that moderate activities possess positive effects on the immune system compared to an inactive, sedentary lifestyle [21]. The positive effects found the basis for sports therapy as an accompanying component in cancer follow-up care [22-24]. Under laboratory or otherwise controlled conditions, e.g. in a sports hall, the intensity and the duration of an activity can rather easily be controlled. In outdoor activities, such control is much more difficult. However, outdoor activities might be much more attractive to many patients and correlate much more with many activities of daily life.
Regarding the physical condition and abilities, the patient in the present study showed impressive improvements in the course of one week of skiing intervention. The interpretation of the immunological parameters is more difficult. Of course, on the basis of $N=1$, no general assumptions can be made. However, in contrast to the healthy CG, the parameters measured in the patient of the present study showed some pronounced differences between the pre-test and the post-test. In accordance with other studies [25], the NK-cell number was markedly decreased in the patient following the immunosuppressive treatment. This parameter showed only minor changes whereas the total lymphocyte population increased close to the median value of the CG which might be interpreted as an improvement of the immunological status [26]. Marked changes were also seen in the B-cell population which decreased from a high level above the upper range of variation of the $C G$ to a value close to its median value.

As several studies suggest that the reaction of immunological parameters is highly dependent on intensity and duration of the activity with effects up to 24 hours after exercise in healthy and trained subjects [5], further studies are needed to evaluate the acute and the long term effects of such interventions in pediatric cancer survivors.

Changes of the immunological parameters are assumed to be caused by stress hormone levels [21]. Accordingly, it is difficult to assess whether the changes are caused by the physical activity alone. The skiing sessions were perceived as moderate according to the patient's comments, suggesting that the positive effects might be caused by the physical activity. As this subjective appraisal cannot be supported by objective measurements, the observed effect might be the result of an interaction of the physical activity and other factors such as the "adventure" of skiing aside the clinical environment and the experience of physical capacity after a long time of poor physical constitution and being dependent on a wheel chair. The present study therefore underlines the meaning of sports therapy in non-laboratory environments in which the effects of duration and intensity of an intervention might be less important since they are embedded in other effects, including psychoneuroimmunological ones $[27,28]$.

\section{Acknowledgements}

The authors thank all the participants for taking part in this study, Lotto-Sport-Stiftung Niedersachsen and Vor-Tour der Hoffnung Rheinland-Pfalz e.V., Inner Wheel Hildesheim, Rotary Club Hildesheim, grüne Damen und Herren $(\mathrm{MHH})$ for financial support and particularly the company Becton Dickinson (BD) GmbH Heidelberg for providing the portable measurement equipment. We also like to explicitly thank Prof. Dirk Reinhardt and all members of the AML BFM Study Group for their 
extensive support for this study.

\section{References}

1. Baik I, Curhan GC, Rimm EB, Bendich A, Willett WC, et al. (2000) A prospective study of age and lifestyle factors in relation to community-acquired pneumonia in US men and women. Arch Intern Med 160: 3082-3088.

2. Pape K, Ryttergaard L, Rotevatn TA, Nielsen BJ, TorpPedersen C, et al. (2016) Leisure-time physical activity and the risk of suspected bacterial infections. Med Sci Sports Exerc 48: 1737-1744.

3. Simpson RJ, Hussain M, Baker F, Bigley AB, Peek MK, et al. (2017) Cardiorespiratory fitness is associated with better control of latent herpesvirus infections in a large ethnically diverse community sample: Evidence from the Texas City Stress and Health Study. Brain Behav Immun 66: 35.

4. Woods JA, Davis JM, Smith JA, Nieman DC (1999) Exercise and cellular innate immune function. Med Sci Sports Exerc 31: 57-66.

5. Gleeson $M(2007)$ Immune function in sport and exercise. J Appl Physiol (1985) 103: 693-699.

6. Fairey AS, Courneya KS, Field CJ, Mackey JR (2002) Physical exercise and immune system function in cancer survivors: a comprehensive review and future directions. Cancer 94: 539-551.

7. Kappel M, Tvede N, Galbo H, Haahr PM, Kjaer M, et al. (1991) Evidence that the effect of physical exercise on NK cell activity is mediated by epinephrine. J Appl Physiol (1985) 70: 2530-2534.

8. Hakim FT, Cepeda R, Kaimei S, Mackall CL, McAtee N, et al. (1997) Constraints on CD4 recovery postchemotherapy in adults: thymic insufficiency and apoptotic decline of expanded peripheral CD4 cells. Blood 90: 3789-3798.

9. Hayes SC, Spence RR, Galvão DA, Newton RU (2009) Australian Association for Exercise and Sport Science position stand: optimising cancer outcomes through exercise. J Sci Med Sport 12: 428-434.

10. Schüle K (1983) Zum Stellenwert der Sport-und Bewegungstherapie bei Patientinnen mit Brust-oder Unterleibskrebs Rehabilitation (Stuttg) 22: 36-39.

11. Baumann FT, Jäger E, Bloch W (2012) Sport und körperliche Aktivität in der Onkologie Berlin: Springer.

12. Duggal NA, Niemiro G, Harridge SDR, Simpson RJ, Lord JM (2019) Can physical activity ameliorate immunosenescence and thereby reduce age-related multi-morbidity? Nature Rev.

13. Haynes BF, Sempowski GD, Wells AF, Hale LP (2000) The human thymus during aging. Immunol Res 22: 253-261.

14. Kurpiers N, Vogler T, Flohr S (2018) Effects of an Intense
One-Week Skiing Program on Balance Abilities in Pediatric Cancer Patients. Int J Sports Exer Med 4: 105.

15. Kurpiers N, Kersting UG (2017) The one-ski-method-effects of an alternative teaching approach on selected movement patterns in alpine skiing. Cogent Soc Sci 3: 11.

16. Creutzig U, Zimmermann M, Bourquin JP, Dworzak MN, Fleischhack G, et al. (2013) Randomized trial comparing liposomal daunorubicin with idarubicin as induction for pediatric acute myeloid leukemia: results from Study AML-BFM 2004. Blood 122: 37-43.

17. Nieman DC, Henson DA, Gusewitch G, Warren BJ, Dotson RC, et al. (1993) Physical activity and immune function in elderly women. Med Sci Sports Exerc 25: 823-831.

18. Baj Z, Kantorski J, Majewska E, Zeman K, Pokoca L, et al. (1994) Immunological status of competitive cyclists before and after the training season. Int J Sports Med 15: 319-324.

19. Pedersen B, Tvede N, Christensen LD, Klarlund K, Kragbak S, et al. (1989) Natural killer cell activity in peripheral blood of highly trained and untrained persons. Int $\mathrm{J}$ Sports Med 10: 129-131.

20. Tvede N, Steensberg J, Baslund Bo, Halkjær-Kristensen J (1991) Cellular immunity in highly trained elite racing cyclists during periods of training with high and low intensity. Scand J Med Sci Sports 1: 163-166.

21. Gleeson M, Bishop NC, Stensel DJ, Lindley MR, Mastana SS, et al. (2011) The anti-inflammatory effects of exercise: mechanisms and implications for the prevention and treatment of disease. Nat Rev Immunol 11: 607-615.

22. Baral E, Kwok S, Berczi I (1991) The influence of estradiol and tamoxifen on the mixed lymphocyte reaction in rats. Immunopharmacology 21: 191-197.

23. Hemilä H (1992) Vitamin C and the common cold. Br J Nutr 67: 3-16.

24. Rank M, Freiberger V, Halle M (2012) Sporttherapie bei Krebserkrankungen. Schattauer Verlag.

25. Papa S, Vitale M, Mazzotti G, Neri LM, Monti G, et al. (1989) Impaired lymphocyte stimulation induced by longterm training. Immunol Lett 22: 29-33.

26. Elfeky R, Lazareva A, Qasim W, Veys P (2019) Immune reconstitution following hematopoietic stem cell transplantation using different stem cell sources. Expert Rev Clin Immunol 15: 735-751.

27. Lutgendorf SK, Sood AK (2011) Biobehavioral factors and cancer progression: physiological pathways and mechanisms. Psychosom Med 73: 724-730.

28. Reiche EM, Nunes SO, Morimoto HK (2004) Stress, depression, the immune system, and cancer. Lancet Oncol 5: 617-625. 